
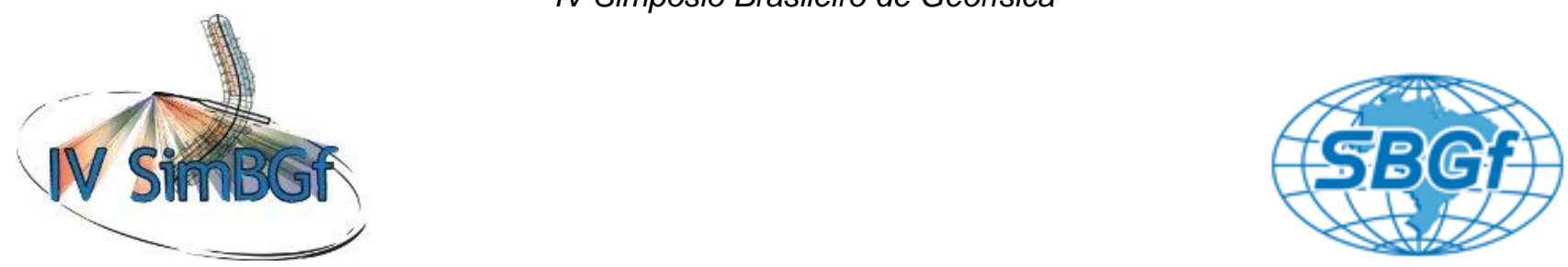

\title{
Processamento sísmico convencional e CRS-2D de dados reais da bacia do Tacutu
}

Rafael dos Santos Furtado, CPGeo e UFPA (Brasil)

Danilo Galvão Ferreira, CPGeo e UFPA (Brasil)

German Garabito, UFRN (Brasil)

Copyright 2010, SBGf - Sociedade Brasileira de Geofísica

Este texto foi preparado para a apresentação no IV Simpósio Brasileiro de Geofísica, Brasília, 14 a 17 de novembro de 2010. Seu conteúdo foi revisado pelo Comité Técnico do IV SimBGf, mas não necessariamente representa a opinião da SBGf ou de seus associados. É proibida a reprodução total ou parcial deste material para propósitos comerciais sem prévia autorização da SBGf.

\section{Abstract}

The Tacutu Basin, located in the Roraima State (Brazil), was the target of a great exploration survey sponsored by PETROBRAS during the 1980 decade, with the objective of assessing the exploration potential of the region. The acquired seismic lines are of low fold and low signal-tonoise ratio. In this context, this work then compares the results of the CMP and CRS stacking methods when applied on the processing of the survey lines 050-RL-086, 050-RL-087, 050-RL-090 and 050-RL-091. The results have shown that the CRS method is more efficient than the CMP method in generating seismic images with a higher resolution and more geologically representative.

\section{Introdução}

A Bacia do Tacutu é formada por sistemas de grábens com direção SE-NW com 300 km de extensão e 30 a 50 $\mathrm{km}$ de largura. Esta bacia desenvolveu-se como um rifte intracontinental na porção central da área cratônica denominada de Escudo das Guianas, localizada na fronteira do estado de Roraima, no Brasil, e o distrito de Rupuruni (EIRAS; KINOSHITA; 1987), na República Cooperativa da Guiana. Isto mostra que a bacia não se limita apenas ao território brasileiro, pois a bacia está parcialmente inserida no território da República da Guiana. As informações provenientes das atividades exploratórias no Brasil e na Guiana forneceram um amplo conhecimento da bacia, permitindo interpretar com mais clareza a evolução geológica do gráben. Segundo Eiras e Kinoshita (op. cit.), o arcabouço sedimentar da Bacia do Tacutu é composto por rochas sedimentares e vulcanosedimentares. Isso resultou na descoberta de óleo nãocomercial em rochas basálticas fraturadas datadas do mesozóico. Entretanto, a ausência de reservatórios arenosos convencionais propícios a acumulação de hidrocarbonetos, fez com que em dezembro de 1987, a PETROBRÁS abandonasse as atividades exploratórias na bacia, direcionando seus investimentos para áreas consideradas com maior potencial para a exploração (SILVEIRA, 2006). O presente trabalho tem como objetivo principal fazer reprocessamento de quatro linhas sísmicas da Bacia do Tacutu aplicando a seqüência convencional de processamento sísmico utilizado na indústria e a técnica moderna de empilhamento CRS. Após as etapas de empilhamento, serão apresentados os resultados da migração tipo Kirchhoff com 0 empilhamento convencional e com empilhamento CRS, com o propósito de produzir imagens sísmicas de melhor resolução, que favoreçam uma análise interpretativa dos dados quanto à detecção de estruturas geológicas da porção brasileira da bacia.

\section{Metodologia/ Problema Investigado}

Algumas das linhas sísmicas de reflexão, oriundas da campanha exploratória promovida pela PETROBRAS, foram adquiridas pelo Centro de Pesquisa em Geologia e Geofísica da Universidade Federal da Bahia (CPGGUFBA), junto à Agência Nacional do Petróleo (ANP) e foram cedidas ao Instituto de Geociências da Universidade Federal do Pará (IG-UFPA) para finalidades acadêmicas. Os dados utilizados neste trabalho são da campanha exploratória realizada no ano de 1981, que são as linhas de sísmica de reflexão 050-RL-086, 050RL-087, 050-RL-090 e 050-RL-091 (Figura 1).

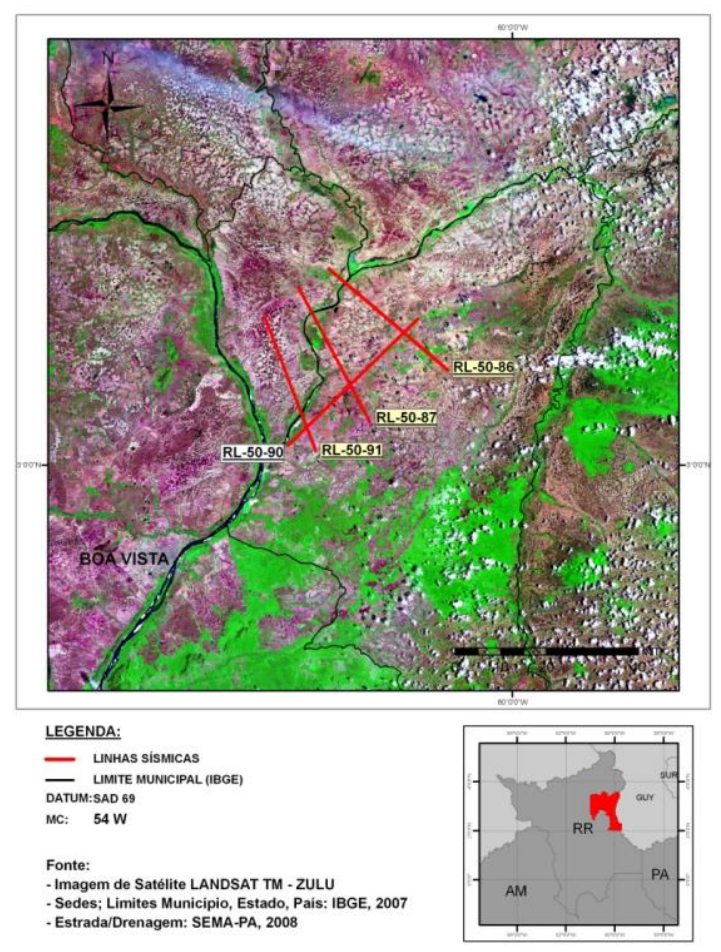

Figura 1- Mapa de localização das linhas 050-RL-086, 050-RL087, 050-RL-090 e 050-RL-091. 
Para todas as etapas de processamento dos dados foi utilizado o aplicativo comercial SeisSpace versão 2003.19.1.1, da Landmark Graphics Corporation, empresa da Halliburton Ltd. Para a aplicação do método CRS utilizou-se o algoritmo desenvolvido em Garabito Callapino et al. (2001) e Garabito Callapino (2001). Para a localização e o georeferenciamento das quatro linhas foi utilizado o programa ArcGis versão 9.2. Essas linhas foram obtidas através do levantamento contínuo/seqüencial que é caracterizado por deslocamentos sucessivos do lanço em uma trajetória mais ou menos retilínea, empregando a técnica de CDP usando o arranjo "split-spread" simétrico nas três linhas. A aquisição das linhas sísmicas deste trabalho foi conduzida com baixa multiplicidade sísmica ou cobertura que é de $1200 \%$ ou de 12 traços por CDP. O grau de cobertura é inversamente proporcional a distância entre pontos de tiro, ou seja, quanto maior a distância entre os pontos de tiro, menor o grau de cobertura do levantamento. Neste trabalho, por questões práticas o processamento dos dados sísmicos foi dividido em duas fases de execução: 0 pré-processamento e 0 processamento avançado. A fase de préprocessamento se refere ás etapas de preparação dos dados (Leitura dos dados e Geometria) e a utilização de técnicas de tratamento do sinal sísmico (Edição dos traços, Filtragem $f-k$ e Deconvolução). A fase de préprocessamento tem como objetivos organizar os dados adquiridos e identificar os possíveis problemas que possam afetar a qualidade dos resultados, tais como, detectar e tratar traços com amplitudes anômalas, tentar reduzir ruídos coerentes entre outros. A Figura 2 ilustra 0 fluxograma do pré-processamento realizado neste trabalho.

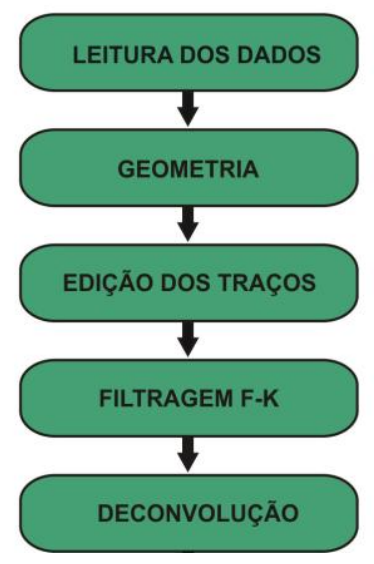

Figura 2 - Fluxograma de pré-processamento.

A fase de processamento avançado envolve técnicas como análise de velocidade, correção NMO, empilhamento CMP e migração pós-empilhamento em tempo. A fase de processamento avançado tem início com a análise de velocidade, que envolve a estimativa indireta das velocidades em subsuperfície. As informações de velocidade são repassadas à próxima etapa para correção de NMO. Após a correção NMO obtém-se uma seção empilhada bruta ou preliminar (brute stack). Estas etapas foram repetidas dentro da rotina de processamento a fim de melhorar a qualidade da seção empilhada resultante. Após essas etapas foi feita a migração pós-empilhamento, com o objetivo de corrigir o posicionamento das estruturas nas seções sísmicas. A seqüência das etapas desenvolvidas nessa fase é ilustrada no fluxograma abaixo (Figura 3).

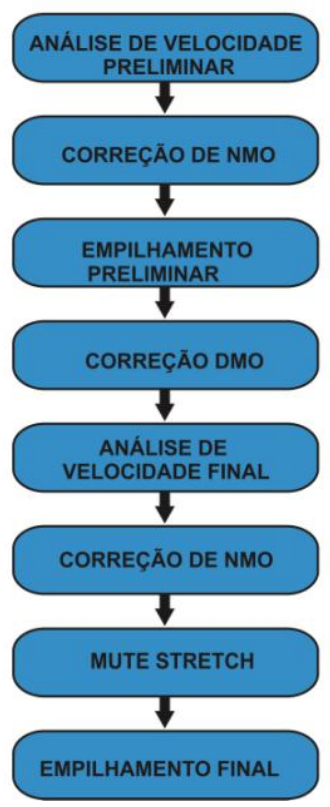

Figura 3 - Fluxograma das etapas de processamento avançado.

\section{Empilhamento Sísmico CMP (NMO/DMO)}

O empilhamento CMP tem como objetivo realizar a soma aritmética das amplitudes dos traços das famílias CMP's, após a correção de NMO, visando aumentar a razão sinal-ruído dos dados, sendo que essa melhoria dependerá do grau de coerência alcançada nos eventos de reflexões. A cada família CMP é aplicada a correção $\mathrm{NMO}$, ou seja, os registros da família são deslocados em tempo ao seu equivalente em afastamento nulo. Todos os traços das famílias CMP que foram corrigidos de NMO são finalmente somados, produzindo um único traço que representa o registro de afastamento nulo na posição de ponto médio CMP (Figura 4). Este procedimento é denominado empilhamento CMP. A vantagem do empilhamento CMP é o aumento significativo da relação sinal/ruído ocasionado pela interferência construtiva de eventos coerentes, tais como: as reflexões primárias e as difrações, além da interferência destrutiva dos ruídos aleatórios.

A seção empilhada de afastamento nulo mostra uma primeira imagem aproximada do modelo geológico estudado e a amplitude dos eventos das interfaces quando preservada ou ponderada durante 0 empilhamento, pode fornecer informações sobre as propriedades das camadas. A qualidade da seção sísmica empilhada obtida dependerá do grau de precisão alcançado na determinação das velocidades das camadas em subsuperfície, ou seja, da análise de velocidade, já que o campo de velocidades nos indica a disposição aproximada das camadas em subsuperfície. 
Portanto, uma boa seção empilhada provém de um ótimo macro-modelo de velocidades e de uma excelente correção de NMO aos dados. Após a correção NMO foi realizada a correção DMO (Dip Moveout) que tem como objetivo a correção dos erros no empilhamento devido a mergulho dos refletores. O DMO corrige nos dados sísmicos pré-empilhados as distorções ocasionadas pela presença de refletores mergulhantes transformando as seções de afastamento não-nulo em seções de afastamento nulo.

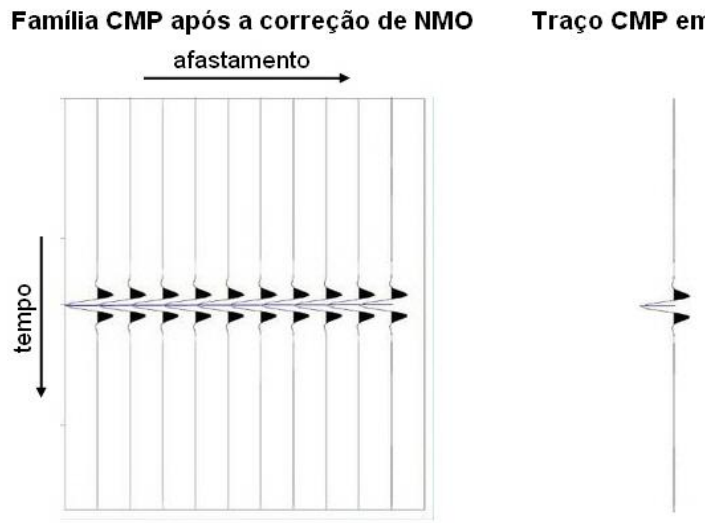

Figura 4 - O empilhamento CMP produz um único traço de afastamento nulo.

Fonte: Adaptado de Yilmaz (1987).

\section{Método de Empilhamento por Superfície de Reflexão Comum (CRS).}

Com objetivo de superar as restrições do empilhamento convencional CMP e melhorar a qualidade do imageamento sísmico, o empilhamento CRS que é um método que simula uma seção afastamento nulo (ZO zero offset) a partir de dados de cobertura múltipla. A técnica de empilhamento CMP assume reflexões correspondentes a um único ponto refletor em profundidade, enquanto que a técnica de empilhamento CRS admite reflexões associadas com um elemento refletor em subsuperfície que é caracterizado pela posição, inclinação e curvatura local do refletor. Esses três parâmetros consistem de um ângulo de emergência $\left(\beta_{0}\right)$, e dos raios de curvatura $\left(\begin{array}{lll}\text { NIP } & N\end{array}\right)$ das ondas hipotéticas Ponto de Incidência Normal e onda Normal. A Figura 5 ilustra a propagação das duas ondas hipotéticas NIP e $\mathrm{N}$ em 2D, num meio formado por duas camadas homogêneas desde o ponto de incidência normal $R$ sobre o refletor até 0 ponto de observação $x_{0}$ na superfície. A onda NIP é uma onda hipotética que se propaga em forma ascendente a partir de uma fonte pontual localizada no ponto R. A Figura 5(a) representa a propagação da onda NIP em diferentes instantes de tempo até atingir o ponto de emergência $x_{0}$. A onda $\mathrm{N}$ também é uma onda hipotética que se propaga a partir de fontes pontuais distribuídas ao longo do refletor, e ativadas no mesmo instante. A Figura 5(b) representa a propagação da onda $\mathrm{N}$ em diferentes instantes de tempo e também associados ao raio normal.

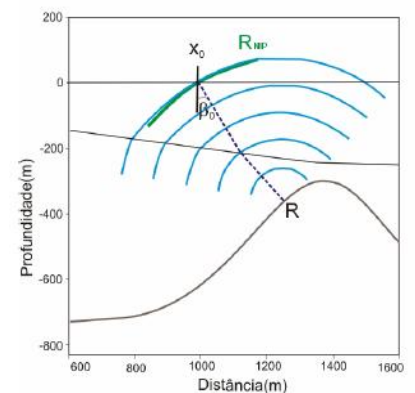

(a)

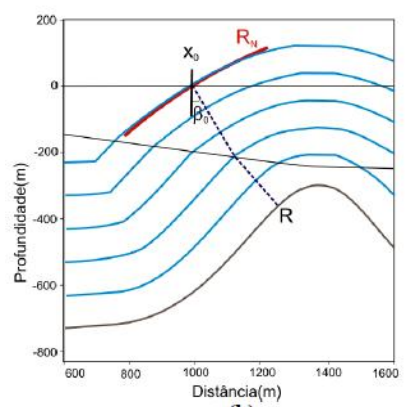

(b)
Figura 5 - Propagação das ondas hipotéticas (a) NIP e (b) Normal em 2D. O raio normal inicia-se em $x_{0}$, propaga-se ao longo das camadas, reflete no ponto $R$ e emerge na superfície de medição em $x_{0}$. $B_{0}$ é o ângulo de incidência normal com a normal á superfície de me medição plana. $R_{N I P}$ e $R_{N}$ são os raios de curvatura das ondas NIP e N.

Fonte: Modificado de Jäger et.al (2001).

Para dados sísmicos configurados em CMP, as aproximações hiperbólicas do tempo de trânsito uniparamétrica ainda é usada habitualmente. Para dados sísmicos de cobertura múltipla ao longo de uma linha sísmica de aquisição, tal procedimento não é diferente, de modo que no empilhamento CRS, as aproximações do tempo de trânsito de segunda ordem tri-paramétrica podem ser usadas.

A aproximação do tempo de trânsito CRS-2D é a aproximação hiperbólica que descreve o tempo de trânsito de raios paraxiais arbitrários na vizinhança de um raio central conhecido em um meio heterogêneo, demonstrada pela teoria paraxial do raio ou pela aproximação geométrica (HÖCHT et al., 1999). Essa aproximação hiperbólica pode ser expressa em termos até $2^{\circ}$ ordem $n$ dos parâmetros cinemáticos $\beta_{0}$, $R_{N I P}$ e $R_{N}$ das auto-ondas NIP e N (TYGEL et. al, 1997):

$t_{C R S}^{2}\left(x_{m}, h\right)=\left(t_{0}+\frac{2 \operatorname{sen} \beta_{0}}{v_{0}}\left(x_{m}-x_{0}\right)\right)^{2}+\frac{2 t_{0} \cos ^{2} \beta_{0}}{v_{0}}\left(\frac{\left(x_{m}-x_{0}\right)^{2}}{R_{N}}+\frac{h^{2}}{R_{N I P}}\right)$

sendo $\boldsymbol{t}_{0}$ o tempo duplo do raio central de afastamento nulo e $\boldsymbol{v}_{\boldsymbol{0}}$ a velocidade próxima a superfície em torno do ponto de emergência do raio central. As coordenadas $\boldsymbol{X}_{m}=\left(\boldsymbol{x}_{g}+\boldsymbol{x}_{s}\right) / \mathbf{2}$ e $\mathrm{h}=\left(\boldsymbol{x}_{g}-\boldsymbol{x}_{s}\right) / \mathbf{2}$ são o ponto médio e o meio afastamento entre a fonte e o receptor, respectivamente. As coordenadas horizontais do par fonte e receptor são $\boldsymbol{x}_{\boldsymbol{s}}$ e $\boldsymbol{x}_{\boldsymbol{g}}$. $\boldsymbol{\beta}_{\boldsymbol{o}}$ é o ângulo de emergência do raio normal com relação a normal da superfície, $\boldsymbol{R}_{\text {NIP }} \mathrm{e}$ $\boldsymbol{R}_{\boldsymbol{N}}$ correspondem aos raios de curvatura da onda NIP e da onda $\boldsymbol{N}$, respectivamente, ambos medidos no ponto de emergência do raio central.

A aproximação do tempo de trânsito CRS representada pela equação 1 , é independente do modelo de velocidades, tal fato que se distingue da aproximação hiperbólica do empilhamento convencional CMP, que depende explicitamente de um macro modelo de velocidades. Entretanto, o único conhecimento a priori de velocidade para a aproximação do tempo de trânsito CRS é o da velocidade próxima á linha de aquisição $\boldsymbol{v}_{\boldsymbol{0}}$. Assim, com as coordenadas $\boldsymbol{x}_{\boldsymbol{m}}$ e $\boldsymbol{h}$ bem definidas e com os três parâmetros cinemáticos $\left(\boldsymbol{\beta}_{0}, \boldsymbol{R}_{\text {NIP }}\right.$ e $\left.\boldsymbol{R}_{N}\right)$ bem determinados para um ponto de amostragem $\boldsymbol{P}_{\boldsymbol{0}}\left(\boldsymbol{x}_{\boldsymbol{0}}, \boldsymbol{t}_{\boldsymbol{0}}\right)$, a 
aproximação do tempo de trânsito CRS define uma superfície ou curva de empilhamento CRS. É também chamada de superfície CRS (GARABITO, 2001)..

A determinação dos três atributos de frentes de ondas do método CRS pode ser realizada através de processos automáticos de busca ou otimização baseados em análise de coerência dos dados sísmicos préprocessados. A estratégia de busca seguida neste trabalho para a adequada determinação dos parâmetros de empilhamento é conhecida como global-local, que foi desenvolvida por Garabito (2001) na Universidade Federal do Pará (Brasil). Nesta estratégia os parâmetros CRS são determinados em três etapas, sendo que nas duas primeiras etapas são determinados os três parâmetros por meio de otimização global e na terceira esses parâmetros são refinados por meio da otimização local (Figura 6).

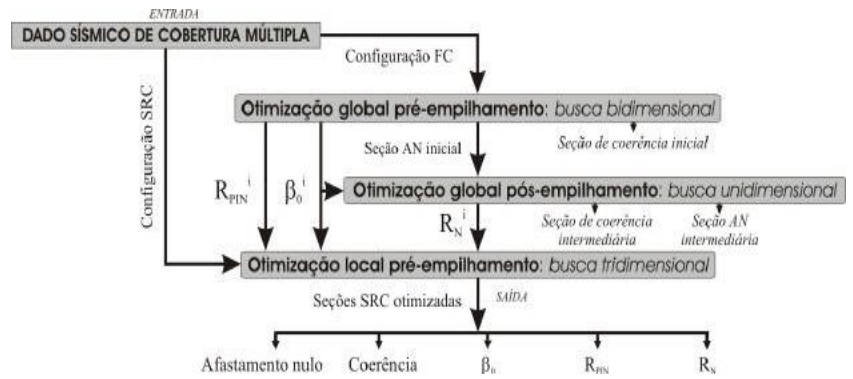

Figura 6 - Fluxograma da estratégia de busca CRS global-local.

\section{Migração} Fonte: Garabito (2001).

A migração tem como objetivo posicionar o mergulho dos refletores para sua posição correta e colapsar as difrações, aumentando assim a resolução espacial e produzindo uma imagem sísmica mais fidedigna da subsuperfície de qualidade. No presente trabalho foi utilizada a migração Kirchhoff pós-empilhamento em tempo, por ter um custo baixo e necessitar de menos tempo e esforço computacional. O objetivo de usar essa migração é tentar gerar seções migradas capazes de proporcionar uma imagem de qualidade dos refletores em subsuperfície.

A migração Kirchhoff se baseia na soma de amplitudes ao longo de curvas de tempo de trânsito de difração ou curvas isócronas, respectivamente.

As correções de amplitude e fase antes do somatório dos dados tornam o método mais consistente com a equação de onda, já que ele incorpora os fatores de divergência esférica, de obliqüidade e de mudança de fase inerente as fontes secundárias de Huygens.

\section{Resultados}

Os resultados das migrações para os diferentes métodos de empilhamento foram organizadas com o objetivo de comparar esses resultados da melhor maneira possível. As Figuras 7, 9,11 e 13 representam as seções migradas após o empilhamento CMP das linhas 050-RL-086, 050RL-087, 050-RL-090 e 050-RL-091, respectivamente. As Figuras 8,10,12 e 14 correspondem às seções migradas após o empilhamento CRS das linhas 050-RL-086, 050RL-087, 050-RL-090 e 050-RL-091, respectivamente. Observou-se que as seções migradas após o empilhamento CRS obtiveram melhor definição dos eventos de reflexão quando comparado as seções migradas após o empilhamento CMP. Apesar da baixa cobertura e baixa razão sinal-ruído dos dados sísmicos, o método CRS conseguiu realçar tanto os refletores rasos quanto os refletores mais profundos, obtendo uma melhora significativa na definição e na continuidade dos refletores sísmicos. Já o método CMP foi comprometido, uma vez que as seções mostraram descontinuidades laterais nos eventos de reflexão em várias partes das seções e péssima resolução dos refletores.

A seção correspondente a linha 050-RL-086, em que foi aplicada a migração após empilhamento CMP, não obteve boa resolução dos eventos de reflexão e nem boa continuidade lateral, principalmente no intervalo de $0,5 \mathrm{~s}$ a 2,0s. Contudo, observou-se que a seção que corresponde a essa mesma linha, em que foi aplicada a migração após o empilhamento CRS, obteve melhor definição dos eventos de reflexão nos intervalos $0,5 \mathrm{~s}$ a 2,0 s, e também obteve uma maior continuidade lateral tanto dos refletores rasos quanto dos profundos (Figuras 7 e 8).

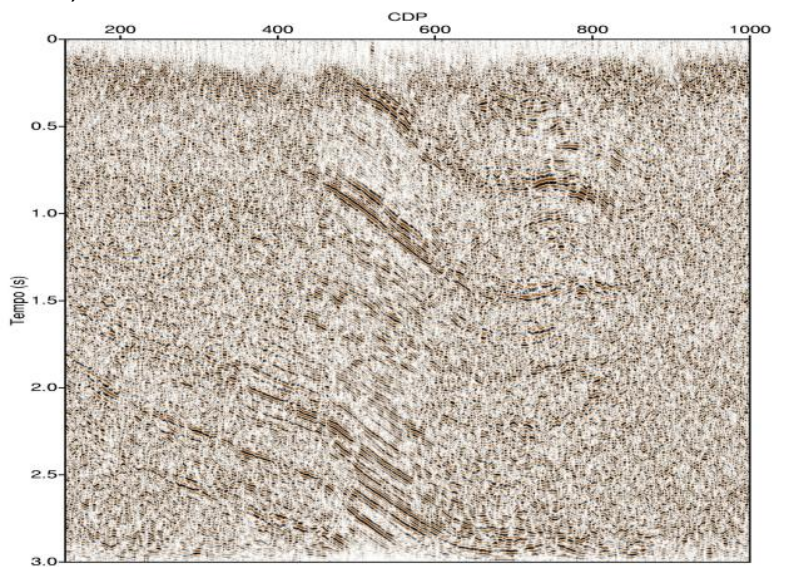

Figura 7 - Seção migrada em tempo após empilhamento CMP, linha 050-RL-086.

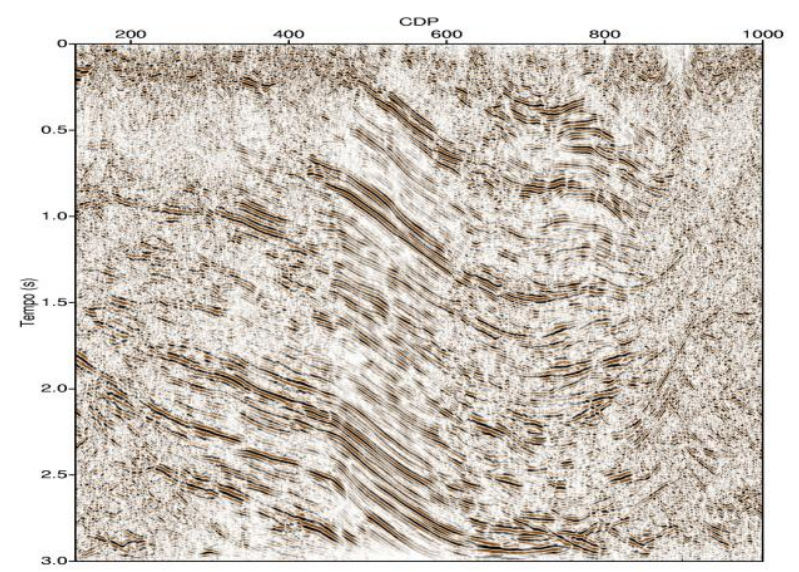

Figura 8 - Seção migrada em tempo após empilhamento CRS; linha 050-RL-086. 
A seção migrada após o empilhamento CMP da linha 050-RL-087 foi comprometida, já que a seção mostrou descontinuidade lateral nos eventos de reflexão e também péssima resolução dos refletores no intervalo de acima de 2,0 entre os CDPs 200 e 600. A seção migrada após o empilhamento CRS da linha 050-RL-087 obteve um aumento significativo na razão sinal-ruído, melhor continuidade lateral nos eventos de reflexão e ótima resolução dos refletores (Figuras 9 e 10).

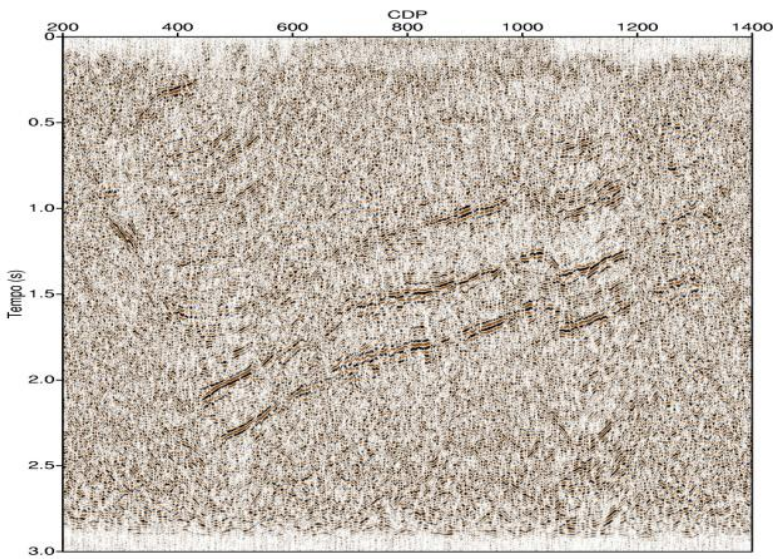

Figura 9 - Seção migrada em tempo após empilhamento CMP, linha 050-RL-087.

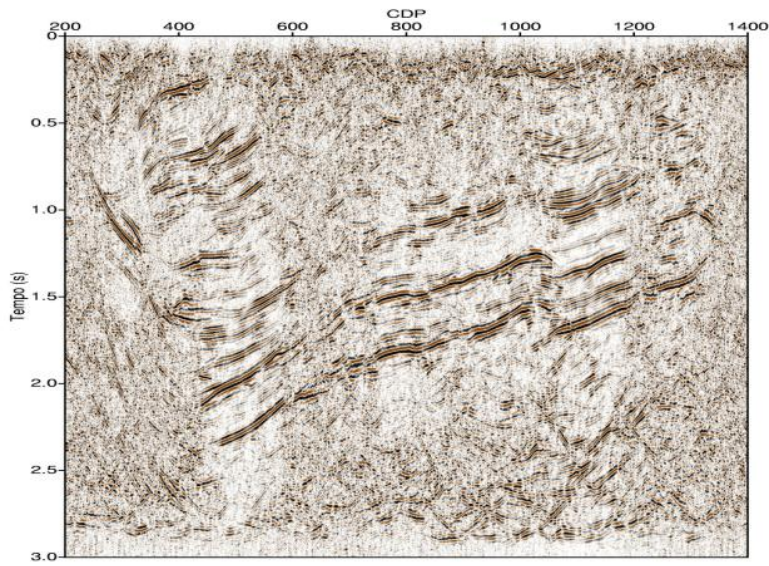

Figura 10 - Seção migrada em tempo após empilhamento CRS; linha 050-RL-087.

As seções correspondentes a linha 050-RL-090 apresentaram boa resolução e continuidade lateral dos refletores. Entretanto, a seção migrada após o empilhamento CRS mostrou melhor continuidade lateral dos eventos de reflexão em toda a seção e principalmente nas posições (CDPs) 0 a 800 , acima de 3s (Figuras 11 e 12).

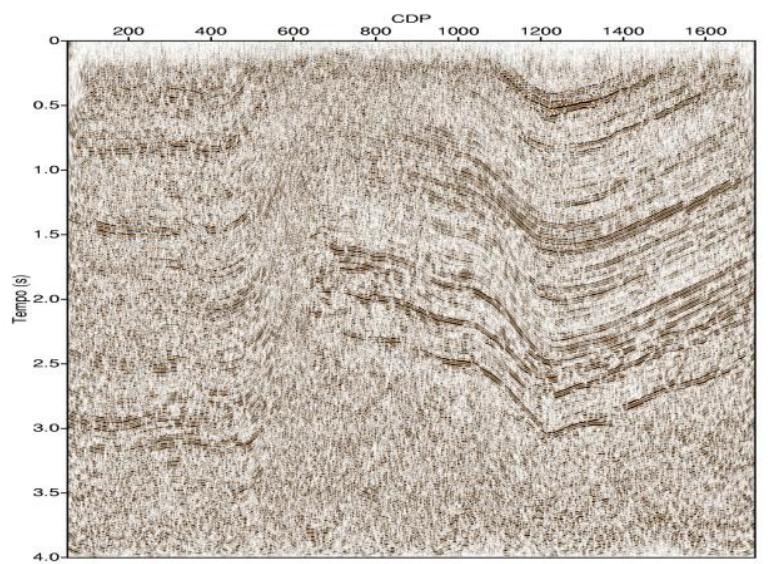

Figura 11 - Seção migrada em tempo após empilhamento CMP, linha 050-RL-090.

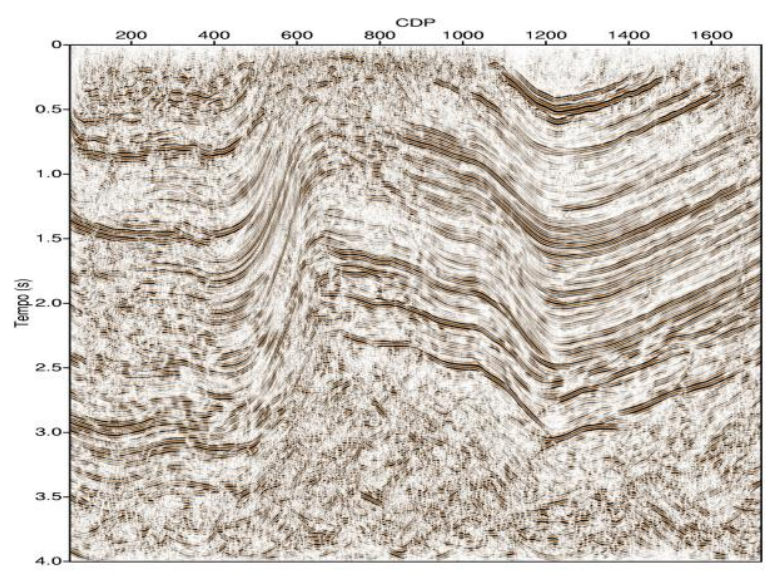

Figura 12 - Seção migrada em tempo após empilhamento CRS; linha 050-RL-090.

A seção migrada após o empilhamento CMP da linha 050-RL-091 mostrou baixa razão sinal-ruído, descontinuidades laterais e péssima resolução nos eventos de reflexão, principalmente nas entre os CDPs 600 a 1000, acima dos 3s. A seção migrada após o empilhamento CRS apresentou um aumento na razão sinal-ruído, melhor continuidade lateral e melhorou a resolução dos refletores (Figuras 13 e 14).

Os exemplos de aplicação mostram que o método CRS apresenta resultados com qualidade superior quando comparados com os resultados do método de empilhamento CMP (NMO/DMO),

Esta melhor qualidade refere-se aumento da razão sinalruído, melhor definição de estruturas complexas, principalmente dos refletores com curvatura e com mergulhos acentuados. 


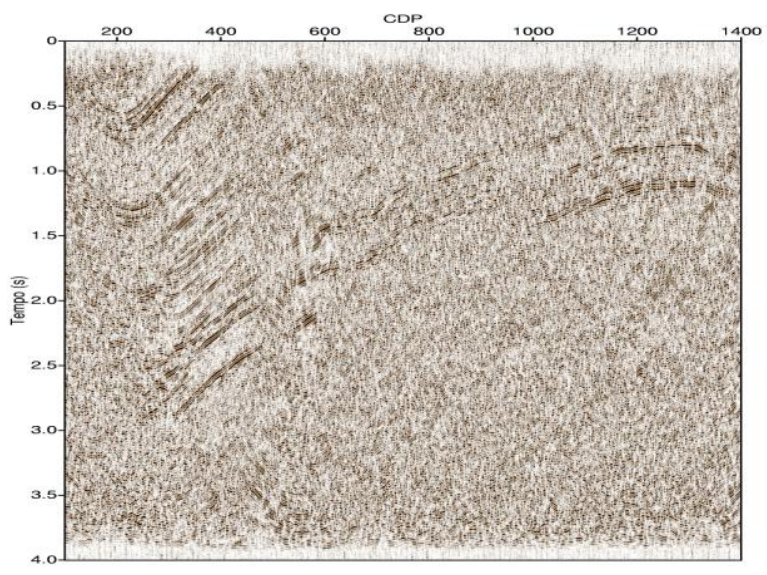

Figura 13 - Seção migrada em tempo após empilhamento CMP, linha 050-RL-091.

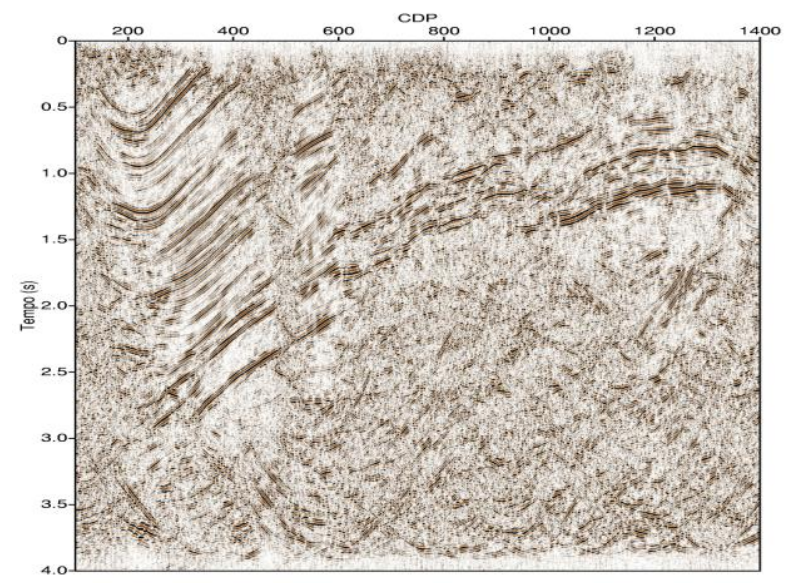

Figura 14 - Seção migrada em tempo após empilhamento CRS; linha 050-RL-091.

\section{Discussão e Conclusões}

A fase de pré-processamento obteve resultados satisfatórios, fato comprovado pelos bons resultados com o processamento convencional e o método CRS. A dificuldade da fase de pré-processamento está diretamente ligada à construção da geometria e a edição de traços. Em relação à geometria, a dificuldade ocorreu devido à falta de informações sobre a aquisição como as coordenadas de fontes e receptores e em relação à edição de traços, por conta da baixa qualidade dos dados sísmicos.

As linhas sísmicas processadas neste trabalho têm como características a baixa multiplicidade sísmica e a baixa razão sinal-ruído. Apesar dessas problemáticas, as seções sísmicas obtidas pelo método de empilhamento CRS mostraram uma razão sinal-ruído superior e uma melhor continuidade lateral dos refletores do que o convencional método de empilhamento CMP. O método de empilhamento CRS obteve excelente qualidade no imageamento de refletores mergulhantes e curvados. Os bons resultados obtidos com o método CRS revelam que este método extrai o máximo de informação possível dos dados sísmicos com baixa qualidade e baixa cobertura, de ambientes geológicos estruturalmente complexos. Este fato é importante, pois na reavaliação de áreas de interesse, o método CRS pode reduzir custos evitando novos levantamentos onde se tem dados antigos.

Devido aos bons resultados obtidos pelo método de empilhamento CRS nas linhas 050-RL-086, 050-RL-087, 050-RL-090 e 050-RL-091 da Bacia do Tacutu, recomenda-se aplicar este método de empilhamento em outras linhas sísmicas da referida bacia, para uma melhor identificação dos refletores em subsuperfície, conseqüentemente para contribuir ao melhor conhecimento geológico da região aliado á um estudo de interpretação das seções sísmicas processadas.

\section{Agradecimentos}

À Universidade Federal do Pará, pelo espaço e equipamentos concedidos.

O primeiro autor agradece a Sociedade Brasileira de Geofísica, pela concessão de bolsa de apoio financeiro ao longo do último ano de graduação.

\section{Referências}

BAZELAIRE, E. de. Normal moveout revisited inhomogeneous media and curved interfaces, Geophysics, v.53, n.2, p. 143-157. 1988.

CLAERBOUT, J. F. Basic Earth Imaging. Stanford: Stanford Exploration Project. 1995. p. 59.

EIRAS, J. F.; KINOSHITA, E. M. Evidências de movimentos transcorrentes na Bacia do Tacutu. In: SEMINÁRIO SOBRE RIFTES INTRACONTINENTAIS, 1., 1987, Rio de Janeiro. Anais... Rio de Janeiro: Petrobras/DEPLEX. 1987.

EIRAS, J. F.; KINOSHITA, E. M. Geologia e Perspectivas Petrolíferas da Bacia do Tacutu. In: GABAGLIA, G. P. R; MILANI, E. J. Origem e evolução de bacias sedimentares. Rio de Janeiro: Petrobras, 1990. 416p. p. 197-220.

EIRAS, J. F. et al. Estratigrafia das bacias sedimentares do Brasil. 1987. 111p. Boletim de Geociências da Petrobras, v. 8, n. 1, p. 17-45, jan-mar. 1994.

GARABITO CALLAPINO, G. C. Empilhamento sísmico por superfície de reflexão comum: um novo algoritmo usando otimização global e local. 2001. $65 f$. Tese (Doutorado), Universidade Federal do Pará, Centro de Geociências, Belém. 2001.

JÄGER, R. The common reflection surface stack: theory and application. 1999. Tese (Mestrado), Universidade de Karlsruhe, Alemanha. 1999.

SILVEIRA, R. L. Análise tectono-estratigráfica do Gráben do Tacutu em território brasileiro. 2006. $139 f$. Tese (Doutorado em Geologia) - Universidade Federal do Rio de Janeiro, Instituto de Geociências, Rio de Janeiro, 2006.

YILMAZ, O. Seismic data processing. Society of Exploration - SEG, Tulsa, Oklahoma, USA. 1987. 526p. 